\section{To screen or not to screen children for hypertension?}

I $\mathrm{n}$ this issue of $J F P$, Smith et al recommend following guidelines from the American Academy of Pediatrics to annually screen children for hypertension (see page 220). This recommendation appears to be at odds with the recent US Preventive Services Task Force (USPSTF) statement that concluded there is insufficient evidence for screening children and adolescents for hypertension. But an "I" recommendation from the USPSTF is not the same as a " $\mathrm{D}$ " recommendation. " $D$ " means don't do it, because the evidence indicates that the harms outweigh the benefits. "I" means we don't have enough evidence to weigh the harms and benefits, so it is up to you and your patients to decide what to do.

So whose recommendations should we follow?

Our decision should be based on a thorough understanding of the evidence, and that evidence is well summarized in the recent USPSTF report. ${ }^{1}$ The reviewers found no studies that evaluated the benefits and harms of screening children and

\section{What we can all agree on is that, when hypertension is identified in a child or adolescent, it is important to determine if there is a treatable cause.} adolescents for hypertension and no studies evaluating disease outcomes from treating hypertension in these patients.

There is, however, an association between elevated blood pressure in childhood and outcomes such as left ventricular hypertrophy and carotid intimal thickness. ${ }^{2}$ Some physicians contend that these "disease-oriented outcomes" are sufficient reason to identify and treat hypertension in children and adolescents. ${ }^{3}$ The USPSTF, however, requires a higher level of evidence that includes patient-oriented outcomes, such as a lower risk of congestive heart failure, renal failure, or death, before recommending treatment. Physicians and patients have to choose what level of evidence is sufficient to take action.

Dr. Smith comments: "As noted in their report, the USPSTF acknowledges that observational studies indicate an association between hypertension in childhood and hypertension in adulthood, but there have been no randomized trials to determine if treating hypertension in children and adolescents reduces risk of cardiovascular events. Although it is a cohort study, not a randomized trial, the ongoing i3C Consortium Outcomes Study ${ }^{4}$ may provide better information to guide decisionmaking for children and adolescents with elevated blood pressure."

What we can all agree on is that, when hypertension is identified in a child or adolescent, it is important to determine if there is a treatable cause of elevated blood pressure such as coarctation of the aorta or renal disease. It is also important to address risk factors for elevated blood pressure and cardiovascular disease, such as obesity, poor dietary habits, and smoking. The treatment is lifestyle modification with diet, exercise, and smoking cessation. JFP
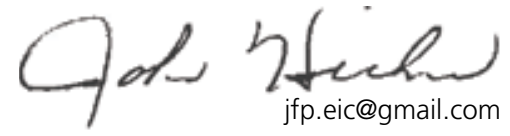

CONTINUED ON PAGE 248

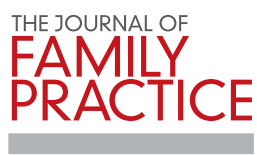

EDITOR-IN-CHIEF

JOHN HICKNER, MD, MSC

Professor Emeritus

Michigan State University

College of Human Medicine

ASSOCIATE EDITOR

RICHARD P. USATINE, MD

University of Texas Health

at San Antonio (Photo Rounds)

ASSISTANT EDITORS

DOUG CAMPOS-OUTCALT, MD, MPA

University of Arizona

RICK GUTHMANN, MD, MPH

Advocate Illinois Masonic Family Medicine

Residency, Chicago

ROBERT B. KELLY, MD, MS

Fairview Hospital, a Cleveland Clinic hospital

GARY KELSBERG, MD, FAAFP

University of Washington, Renton

COREY LYON, DO

University of Colorado, Denver

KATE ROWLAND, MD, MS

Rush-Copley Medical Center, Chicago

E. CHRIS VINCENT, MD

University of Washington, Seattle

EDITORIAL BOARD

FREDERICK CHEN, MD, MPH

University of Washington, Seattle

MARK S. JOHNSON, MD, MPH

Howard University College of Medicine

Washington, DC

JEFFREY T. KIRCHNER, DO, FAAFP, AAHIVS

Penn Medicine/Lancaster General Hospital, PA

TRACY MAHVAN, PHARMD

University of Wyoming, Laramie

MICHAEL MENDOZA, MD, MPH, MS, FAAFP

University of Rochester, NY

FRED MISER, MD, MA

The Ohio State University, Columbus

KEVIN PETERSON, MD, MPH

University of Minnesota, St. Paul

MICHAEL RADDOCK, MD

The MetroHealth System, Cleveland, $\mathrm{OH}$

KATE ROWLAND, MD, MS

Rush-Copley Medical Center, Chicago

LINDA SPEER, MD

University of Toledo, $\mathrm{OH}$

DIRECT INQUIRIES TO:

Frontline Medical Communications

7 Century Drive, Suite 302

Parsippany, NJ 07054

Telephone: (973) 206-3434

Fax: (973) 206-9378

Have a comment or

feedback?

Email: jfp.eic@gmail.com 
1. USPSTF: High blood pressure in children and adolescents: screening. Accessed June 2, 2021. https://uspreventiveservicestaskforce.org/uspstf/recommendation/blood-pressure-in-children-and-adolescents-hypertension-screening

2. Yang L, Magnussen CG, Yang L, et al. Elevated blood pressure in childhood or adolescence and cardiovascular outcomes in adulthood: a systematic review. Hypertension. 2020;75:948-955. doi: 10.1161/hypertensionaha.119.14168
3. Falkner B, Lurbe E. The USPSTF call to inaction on blood pressure screening in children and adolescents. Pediatr Nephrol. 2021;36:1327-1329. doi: 10.1007/s00467-021-04926-y

4. Sinaiko AR, Jacobs DR Jr, Woo JG, et al. The International Childhood Cardiovascular Cohort (i3C) consortium outcomes study of childhood cardiovascular risk factors and adult cardiovascular morbidity and mortality: Design and recruitment. Contemp Clin Trials. 2018;69:55-64. doi: 10.1016/j.cct.2018.04.009 